OP24

\title{
NOCTURNAL MELATONIN SUPPRESSION BY ADOLESCENTS AND ADULTS FOR DIFFERENT LEVELS, SPECTRA, AND DURATIONS
}

\author{
Mariana Figueiro et al.
}

DOI 10.25039/x46.2019.OP24

from

CIE x046:2019

Proceedings

of the

29th CIE SESSION

Washington D.C., USA, June 14 - 22, 2019

(DOI 10.25039/x46.2019)

The paper has been presented at the 29th CIE Session, Washington D.C., USA, June 14-22, 2019. It has not been peer-reviewed by CIE.

\section{(C) CIE 2019}

All rights reserved. Unless otherwise specified, no part of this publication may be reproduced or utilized in any form or by any means, electronic or mechanical, including photocopying and microfilm, without permission in writing from CIE Central Bureau at the address below. Any mention of organizations or products does not imply endorsement by the CIE.

This paper is made available open access for individual use. However, in all other cases all rights are reserved unless explicit permission is sought from and given by the CIE.

CIE Central Bureau

Babenbergerstrasse 9

A-1010 Vienna

Austria

Tel.: +4317143187

e-mail: ciecb@cie.co.at

www.cie.co.at 


\title{
NOCTURNAL MELATONIN SUPPRESSION BY ADOLESCENTS AND ADULTS FOR DIFFERENT LEVELS, SPECTRA, AND DURATIONS OF LIGHT EXPOSURE
}

\author{
Figueiro, M.G. ${ }^{1}$, Nagare, R. ${ }^{1}$, Rea, M.S. ${ }^{1}$ \\ ${ }^{1}$ Lighting Research Center, Rensselaer Polytechnic Institute, Troy, NY, USA \\ figuem@rpi.edu
}

DOI 10.25039/x46.2019.OP24

\begin{abstract}
The 24-h pattern of light and dark on the retinas is the primary cue for entraining the human circadian system to the solar day, and nocturnal melatonin suppression is a primary marker of the biological clock's response to those light exposures. The development of circadian-effective lighting recommendations and light-treatment methods have been impeded by limited data relating to the combined effects of light level, spectrum, and exposure duration on nocturnal melatonin suppression. This study's primary goal was to measure nocturnal melatonin suppression for a wide range of light levels, 2 white light spectra, and extended exposure durations. The study also sought to provide an estimate of the absolute threshold for the impact of light on acute nocturnal melatonin suppression and to determine whether adolescents were more sensitive to short-wavelength light than middle-aged adults. Results showed significant main effects of light level, spectrum, and exposure duration on melatonin suppression.
\end{abstract}

Keywords: Circadian Phase; Circadian Phototransduction; Circadian Rhythms; Nocturnal Melatonin Suppression; Light Level, Exposure Duration, and Spectrum; White Light

\section{Motivation, Specific Objectives}

The human circadian system is primarily regulated by the 24-h light-dark cycle incident on the retina, and nocturnal melatonin suppression is a primary outcome measure for characterizing the biological clock's response to those light exposures. A limited amount of data related to the combined effects of light level, spectrum, and exposure duration on nocturnal melatonin suppression has impeded the development of circadian-effective lighting recommendations and light-treatment methods.

Based in part upon the published light-induced nocturnal melatonin suppression data (Brainard et al., 2001, Thapan et al., 2001), a model of human circadian phototransduction was proposed (Rea et al., 2005, Rea et al., 2012, Rea and Figueiro, 2018). Importantly, the model was constrained by fundamental knowledge of retinal neurophysiology and neuroanatomy. Operationally, the model provides a framework for depicting how the classical photoreceptors (i.e. rods and cones) provide input to the intrinsically photosensitive retinal ganglion cells (ipRGCs) (Güler et al., 2008), which are the main conduit of electrical signals from the retinas to the master clock in the suprachiasmatic nuclei of the anterior hypothalamus, where the biological clock is located. Mathematically, for any light source, the model converts the spectral irradiance at the cornea into units of circadian light $\left(C L_{A}\right)$, reflecting the spectral sensitivity of the circadian system, and then transforms those values into the circadian stimulus (CS) scale value reflecting the absolute sensitivity of the circadian system (Rea et al., 2005, Rea et al., 2012, Rea and Figueiro, 2018). Thus, CS is a measure of the effectiveness of the retinal light stimulus for the human circadian system from threshold $(C S=0,10)$ to saturation $(C S=0,70)$.

The study's primary goal was to measure nocturnal melatonin suppression for wide ranges of light levels (40-1000 Ix), 2 white light spectra $(2700 \mathrm{~K}$ and $6500 \mathrm{~K})$, and light exposure durations $(0,5-3,0 \mathrm{~h})$. The exposure duration was limited to $3 \mathrm{~h}$ because our previous research identified an upper limit of response saturation after $3 \mathrm{~h}$ of night-time light exposure (Nagare et al., $2018 \mathrm{~b}$ ). The study also sought to provide an accurate estimate of the absolute threshold for light's impact on acute melatonin suppression. Given that previous research showed an 
increased sensitivity in adolescents compared to older adults, 2 groups of participants (teenagers and middle-aged adults) were recruited for the study.

\section{Methods}

\subsection{Participants}

This 10-week study was conducted in two 5 -week sessions with participants from 2 different age groups (i.e. adolescents and adults). The first session employed 16 adolescent participants (aged 13-18 years, mean [SD] age 15,9 years [1,1]; 9 females) and 16 adult participants (aged 24-55 years, mean [SD] age 42,4 years [10,9]; 8 females). The second session employed 17 adolescent participants (aged 14-18 years, mean [SD] age 16,0 years [1,1]; 9 females) and 16 adult participants (aged 26-54 years, mean [SD] age 38,7 years [11,6]; 8 females). Twenty-four of the 32 session 1 participants took part in session 2, joined by 9 new participants (2 adolescents, 7 adults), for a total of 41 unique participants (18 adolescents, 23 adults).

All participants were pre-screened for major health problems such as bipolar disorder, seasonal depression, cardiovascular disease, diabetes, and high blood pressure. Participants were excluded from the study if they were taking over-the-counter melatonin or any prescription medications (e.g. blood pressure medicine, antidepressants, sleep medicine, or beta-blockers). They were also excluded if they reported an eye disease (e.g. cataracts, glaucoma, etc.) or had scheduled trans-meridian travel during the course of the study.

All participants were either attending school or regularly employed, so they were able to follow a consistent sleep-wake schedule (bedtimes no later than 23:00 and wake times no later than 07:30) during the week preceding each study night. Compliance for the adolescent participants was verified using digital wrist-worn actigraphs (Actiwatch 2, Philips Respironics, Murrysville, PA, US) and sleep logs. Adult participants were not required to wear actigraphs or keep a sleep log because they all reported being employed and having regular wake and sleep times during the week. Participants were also required to refrain from caffeine consumption for $12 \mathrm{~h}$ prior to the start of each study night. None of the participants reported difficulties in complying with the schedule or caffeine restriction over the course of the study.

This study conformed to the Code of Federal Regulations (CFR) document Protection of Human Subjects, 45 CFR 46, (2018), and international ethical standards (Portaluppi et al., 2010). It was reviewed, approved, and monitored by Rensselaer Polytechnic Institute's Institutional Review Board. Informed consent was obtained from all study participants and/or their legal guardians.

\subsection{Experimental Conditions, Lighting Apparatus, and Protocol}

Over the course of the study, all participants were exposed to 2 white light sources (Figure 1) with correlated colour temperatures (CCTs) of $2627 \mathrm{~K}(2700 \mathrm{~K}$ rated) and $5936 \mathrm{~K}(6500 \mathrm{~K}$ rated). Both spectra were delivered across a range of illuminance levels (40-1000 photopic Ix at the retinas) to provide 4 target CS levels of $0,07,0,14,0,30$, and 0,50 (Figure 2).

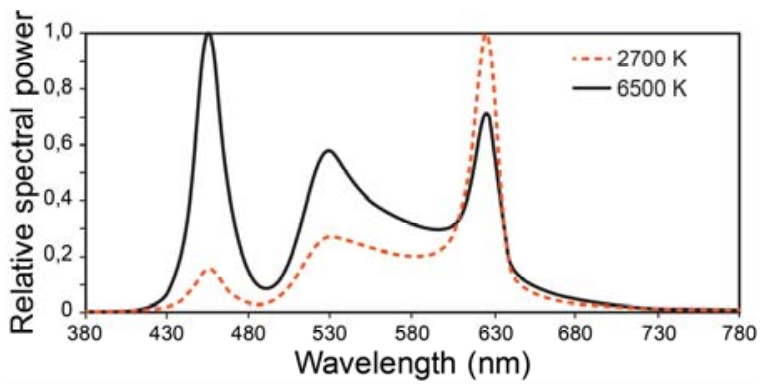

Figure 1 - The spectral power distributions of the rated $2700 \mathrm{~K}$ and $6500 \mathrm{~K}$ LED white light sources used in the study

The lighting interventions were delivered using custom-built desktop luminaires (Figure 3a), each housing 2 high-output linear accent, RGB colour-tuneable LED luminaires (model G2, Ketra, Austin, TX, US) that were aligned end to end and covered by a domed, translucent acrylic 
light diffuser (Utilitech Pro Wrap shop light, Lowe's, Mooresville, NC, US). The luminaires were pre-programmed for the desired output modes (i.e. spectrum and light level), driven by a dedicated satellite link controller (model N3, Ketra), and equipped with a touchpad interface (model X1, Ketra). Each desktop luminaire measured approximately $60 \mathrm{~cm}$ long $\times 20 \mathrm{~cm}$ high $\times$ $20 \mathrm{~cm}$ deep.

The desktop luminaires were positioned on participants' desks on a $30 \mathrm{~cm}$ high supporting stand (see Figure 3b). To monitor the retinal light exposures experienced under the experimental conditions, each participant was provided with lensless eyeglasses frames fitted with a Daysimeter (Bierman et al., 2005, Figueiro et al., 2013), a calibrated light meter. During each data collection period, light levels at participants' eyes were also spot-checked hourly using a spectrometer (Model USB650 Red Tide Spectrometer, Ocean Optics, Winter Park, FL, US) and monitored continually using an illuminance meter.

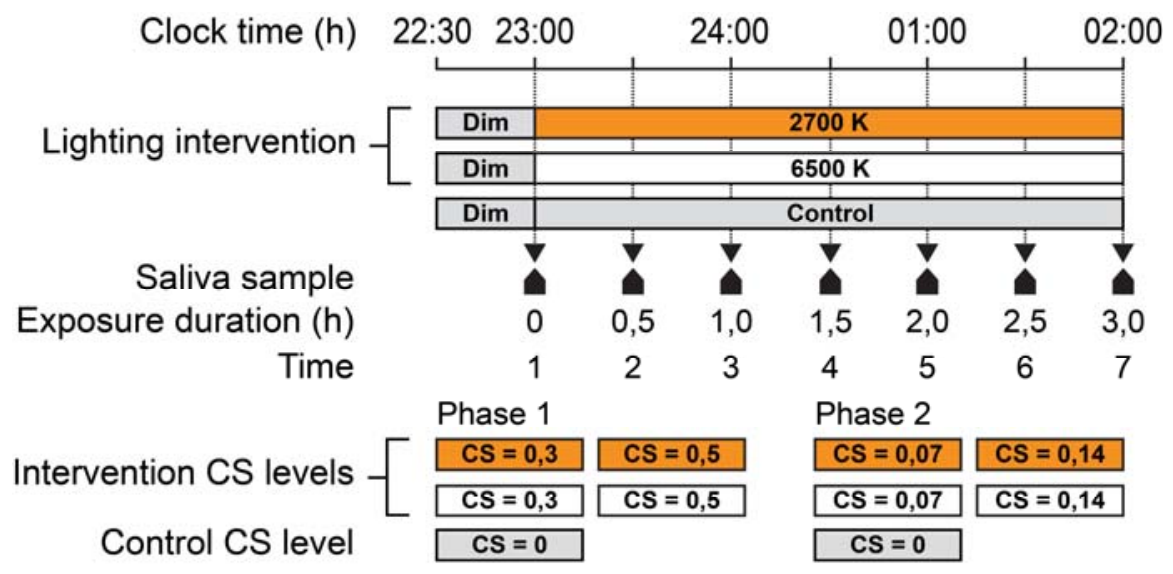

Figure 2 - The study protocol

During both study sessions, participants arrived at the laboratory by $22: 30$ and remained in dim light (<5 Ix at the eyes) for $30 \mathrm{~min}$, followed by a 3-h exposure to one of the 4 lighting interventions (i.e. 2 spectra $\times 2$ target CS levels) or dim light. In order to counter a potential subject-expectancy effect, no information concerning the pre-determined, counter-balanced order of experimental conditions was provided to the participants, although subjective assessments were not conducted to ascertain whether the participants could differentiate between the 2 spectra. Over the course of each study night, 7 saliva samples were collected from each participant; the first sample was taken immediately before commencement of the lighting condition after a 30-min dim light exposure, and 6 additional samples were taken thereafter at 30-min intervals (see Figure 2). After the final saliva sample was collected at 02:00, the participants were free to go home.
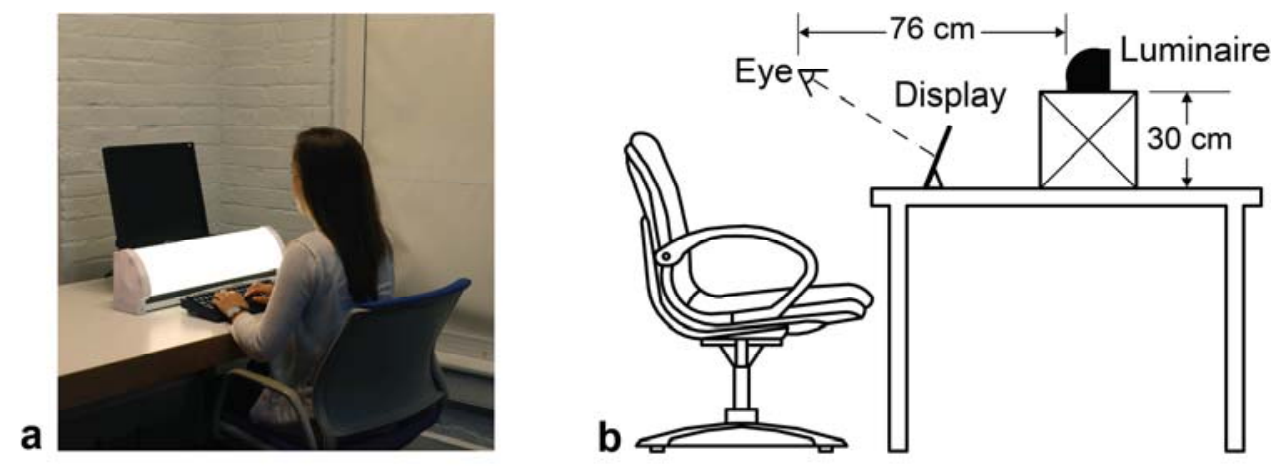

Figure 3 - (a) Example of the desktop luminaire in the study (shown in $6500 \mathrm{~K}$ mode, without supporting stand) and (b) the typical viewing geometry experienced by the participants

During the experiment, the participants were required to refrain from consuming food of any kind and allotted a 10-min window (following the collection of each saliva sample) to drink water. Participants were not required to look directly at the light, but were instructed to face the desktop 
luminaire to ensure minimum variability with respect to the target stimulus. They were also instructed to keep their eyes open at all times and neither block nor remove the eyeglassesmounted Daysimeter, which recorded the actual light stimulus delivered at the eyes. Bathroom breaks for all participants were logged and verified using the Daysimeter data. Participants were free to operate their personal electronic devices (i.e. computers, tablets, cell phones, etc.) on all study nights. All device displays were dimmed and covered with orange-tinted media (Roscolux \#21 golden amber, Rosco Laboratories, Stamford, CT, US) that filtered out radiation $<525 \mathrm{~nm}$ to prevent participants from receiving additional CS from their self-luminous devices. In a previous study, photometric measurements of the stimulus emitted by similarly filtered electronic displays revealed increased light levels of $<5 \mathrm{Ix}$, which translated to a CS of $<0,001$ (Nagare et al., 2018a). Periodic visual monitoring was carried out to ensure compliance with the experimental protocol and confirm that none of the participants closed their eyes.

Saliva samples were collected using the Salivette system (Sarstedt, Nümbrecht, DE), wherein the participant chews on a plain cotton cylinder for an average of 1-2 min. (The participants were not individually timed during the sample collection.) The samples were then placed in a test tube, centrifuged for $5 \mathrm{~min}$ at $1000 \mathrm{~g}$, and immediately frozen $\left(-20^{\circ} \mathrm{C}\right)$. The frozen samples were assayed in a single batch using melatonin radioimmunoassay kits (Direct Melatonin RIA, ALPCO, Salem, NH, US). The reported sensitivity of the saliva sample assay was $1 \mathrm{pg} / \mathrm{mL}$ and the intra- and inter-assay coefficients of variability were $11 \%$ and $14 \%$, respectively.

\subsection{Data Analysis}

Melatonin suppression for each condition was determined by comparing the normalized melatonin levels collected during the dim light condition (the baseline control) to the normalized levels collected at the corresponding time on each lighting intervention night. For each study night, melatonin concentrations at 6 time points during the 3 -h exposures were first normalized to the value for the first sample taken at 23:00 (see Figure 2), and the melatonin suppression at each of those times was then calculated using the following formula:

$$
\text { Percent suppression }=\left[1-\left(\frac{M_{n}}{M_{d}}\right)\right] \times 100
$$

where $M_{n}$ is the normalized melatonin concentration at each time on respective intervention nights and $M_{d}$ is the normalized melatonin concentration at each time on the dim light control night.

None of the adult participants had missing data. Within the adolescent group, melatonin data were unavailable for 3 participants exposed to the $6500 \mathrm{~K}$ source at CS 0,14 due to participant absence. Furthermore, salivary melatonin samples could not be processed for a single participant in the $6500 \mathrm{~K}(\mathrm{CS}=0,5)$ and $2700 \mathrm{~K}(\mathrm{CS}=0,5)$ lighting conditions, for a participant in the $2700 \mathrm{~K}(\mathrm{CS}=0,3)$ lighting condition, and for a participant in the $6500 \mathrm{~K}(\mathrm{CS}=0,14)$ lighting condition (Figure 5) because insufficient saliva (i.e. less than $1 \mathrm{~mL}$ ) was provided the assays.

The linear mixed effect model included all 41 participants recruited for the study and contained one between fixed factor (age group), 3 within fixed factors (spectrum, CS, and time), and one random factor (participant). The between fixed factor age group contained 2 levels (adolescents and adults). The within fixed factor spectrum contained 2 levels $(2700 \mathrm{~K}$ normalized to dim and $6500 \mathrm{~K}$ normalized to dim). The within fixed factor CS contained 4 levels $(0,07,0,14,0,3$, and $0,5)$. Twenty-four participants competed both sessions of the study, and therefore had data for all 4 CS levels. Eight participants only completed Phase 1, and therefore had complete data for 2 CS levels. Nine participants only completed Phase 2, and therefore had complete data for 2 CS levels. The within factor of time contained 6 levels (Times 2-7).

To determine whether the lighting interventions were applied at the same circadian phase for the 2 study sessions and for both age groups, the melatonin levels collected at Time 1 were subjected to analysis of variance (ANOVA) using SPSS statistical software (SPSS version 25, IBM, Armonk, NY, US).

When reporting a significant main effect of an independent variable (e.g. white light spectra), the responses for the dependent variable were averaged across all other independent variables. Further evaluation for main effects and interactions was performed using post hoc 2-tailed, 
Student's $t$-tests with Bonferroni corrections. In some instances, effects were also evaluated using post hoc 1 -sample $t$-tests. The results of the ANOVA and all $t$-tests were considered to be statistically significant if the resulting $p$ value was less than 0,05 .

\section{Results}

\subsection{Photometric Analysis}

The photometric characteristics of the experimental lighting interventions as reliably measured by the spectrometer are provided in Table 1.

Table 1 - Mean (SD) photopic illuminance (in Ix) values obtained during the study nights using the spectrometer and the corresponding CS values obtained using the spectrometer data and the Rea et al. model of circadian phototransduction ${ }^{\mathrm{a}}$

\begin{tabular}{|c|c|c|c|c|c|}
\hline \multirow{2}{*}{$\begin{array}{l}\text { Target } \\
\text { CS }\end{array}$} & \multirow{2}{*}{$\begin{array}{l}\text { White } \\
\text { light } \\
\text { spectrum }\end{array}$} & \multicolumn{2}{|l|}{ Adolescents } & \multicolumn{2}{|l|}{ Adults } \\
\hline & & $\begin{array}{l}\text { Photopic } \\
\text { Illuminance } \\
\text { (Ix) }\end{array}$ & CS & $\begin{array}{l}\text { Photopic } \\
\text { Illuminance } \\
\text { (Ix) }\end{array}$ & CS \\
\hline \multirow{2}{*}{0,07} & $2700 \mathrm{~K}$ & $53(9)$ & $0,06(0,01)$ & $56(13)$ & $0,07(0,01)$ \\
\hline & $6500 \mathrm{~K}$ & $32(4)$ & $0,06(0,01)$ & $31(5)$ & $0,05(0,01)$ \\
\hline \multirow[t]{2}{*}{0,14} & $2700 \mathrm{~K}$ & $100(26)$ & $0,11(0,03)$ & 109 (17) & $0,12(0,02)$ \\
\hline & $6500 \mathrm{~K}$ & $62(5)$ & $0,11(0,01)$ & $66(10)$ & $0,11(0,02)$ \\
\hline \multirow[t]{2}{*}{0,30} & $2700 \mathrm{~K}$ & $282(51)$ & $0,27(0,06)$ & $290(39)$ & $0,27(0,05)$ \\
\hline & $6500 \mathrm{~K}$ & $195(35)$ & $0,27(0,06)$ & $213(49)$ & $0,29(0,08)$ \\
\hline \multirow[t]{2}{*}{0,50} & $2700 \mathrm{~K}$ & $747(102)$ & $0,45(0,12)$ & $773(116)$ & $0,45(0,13)$ \\
\hline & $6500 \mathrm{~K}$ & $467(65)$ & $0,44(0,11)$ & $536(84)$ & $0,47(0,14)$ \\
\hline
\end{tabular}

NOTES: (a) (Rea et al., 2005, Rea et al., 2012, Rea and Figueiro, 2018).

\subsection{Statistical Analysis}

Absolute baseline melatonin levels recorded at the beginning of each study night (Time 1) were not significantly different across the 2 study phases $\left(F_{1,152}=0,11, p=0,74\right)$ and the 2 age groups $\left(F_{1,152}=0,53, p=0,49\right)$, supporting the inference that the light treatment was delivered to all participants at a similar circadian phase in both study sessions. The predicted betweengroups main effect of participant age for nocturnal melatonin suppression was not statistically significant $\left(F_{1,39}=0,19, p=0,67\right)$. The 2-way interactions between participant age group and other independent variables (white light spectra, light level, and exposure duration) were also not statistically different $(p>0,5)$. Since there was no evidence that circadian phase differed for the 2 sessions and for the 2 age groups, subsequent analyses are based upon data combined across both groups.

A significant main effect of photopic light level on melatonin suppression was observed $\left(F_{7,994}\right.$ $=110,1, p<0,001)$, wherein higher photopic light levels were associated with greater melatonin suppression. The analysis also revealed a significant main effect of target CS levels on melatonin suppression $\left(F_{3,159}=91,8, p<0,001\right)$, whereby a higher target $C S$ level was associated with greater suppression (Figure 4 ). 


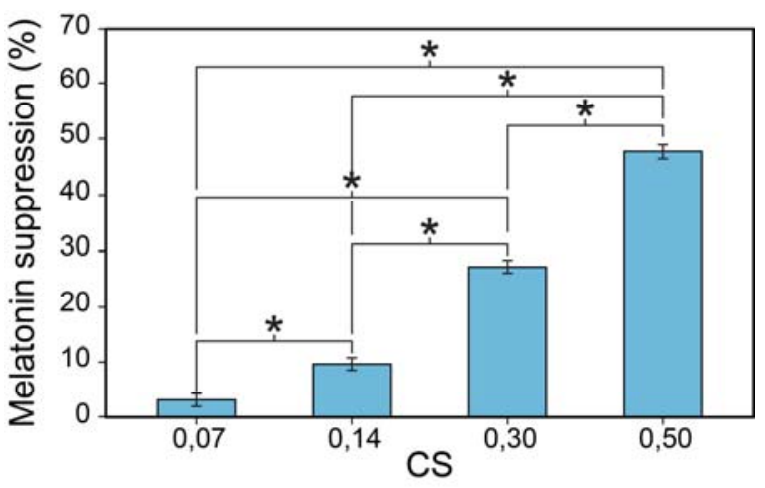

Figure 4 - The significant main effect of CS level. The asterisks represent $p<0,05$ and the error bars represent standard error of the mean (SEM)

There was a significant main effect of white light spectra CCT $\left(F_{1,39}=8,3, p<0,01\right)$; at the same CS level, mean melatonin suppression was greater for the $6500 \mathrm{~K}$ source (mean \pm SEM $=24,7 \pm 1,0 \%$ ) compared to the $2700 \mathrm{~K}$ source (mean $\pm \mathrm{SEM}=18,4 \pm 1,0 \%$ ), suggesting that the phototransduction model is either over-predicting the response to the $2700 \mathrm{~K}$ source or under-predicting the response to the $6500 \mathrm{~K}$ source. Figure 5 compares model predictions (solid line) with the actual data for the $6500 \mathrm{~K}$ and the $2700 \mathrm{~K}$ sources.

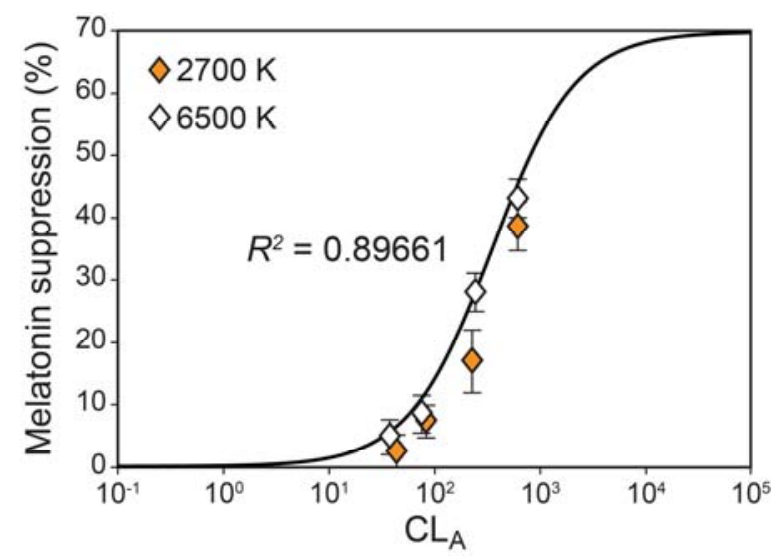

Figure 5 - Model predictions (solid line) plotted with the mean melatonin suppression following 1-h exposure to the $2700 \mathrm{~K}$ and the $6500 \mathrm{~K}$ light sources. The error bars represent SEM

The analysis also revealed a significant main effect of exposure duration $\left(F_{5,1185}=92,5, p<\right.$ $0,001)$, indicating that longer exposure durations suppressed melatonin to a greater degree during participants' biological night (Figure 6a). The analysis did not reveal a significant interaction between spectrum and exposure duration on melatonin suppression $\left(F_{5,1185}=1,99\right.$, $p=0,08)$, suggesting that the spectral sensitivity of acute melatonin suppression does not change with exposure duration. There was, however, a statistically significant interaction between the effects of CS level and exposure duration on melatonin suppression $\left(F_{15,1185}=\right.$ $13,1, p<0,001)$. At lower CS levels, longer exposure durations are required for significant melatonin suppression, whereas significant suppression is observed within 30 min at higher CS levels (see Figure 6b). In terms of absolute threshold for melatonin suppression, exposure to a $C S=0,07$ never reached threshold $(C S=0,1)$ after 3 . In terms of photopic illuminance, these data suggest that it would require 3-h exposures at the eyes of approximately $42 \mathrm{Ix}$ and $95 \mathrm{Ix}$ for the $6500 \mathrm{~K}$ and the $2700 \mathrm{~K}$ sources, respectively, to reach a threshold criterion of $\mathrm{CS}=0,10$. 

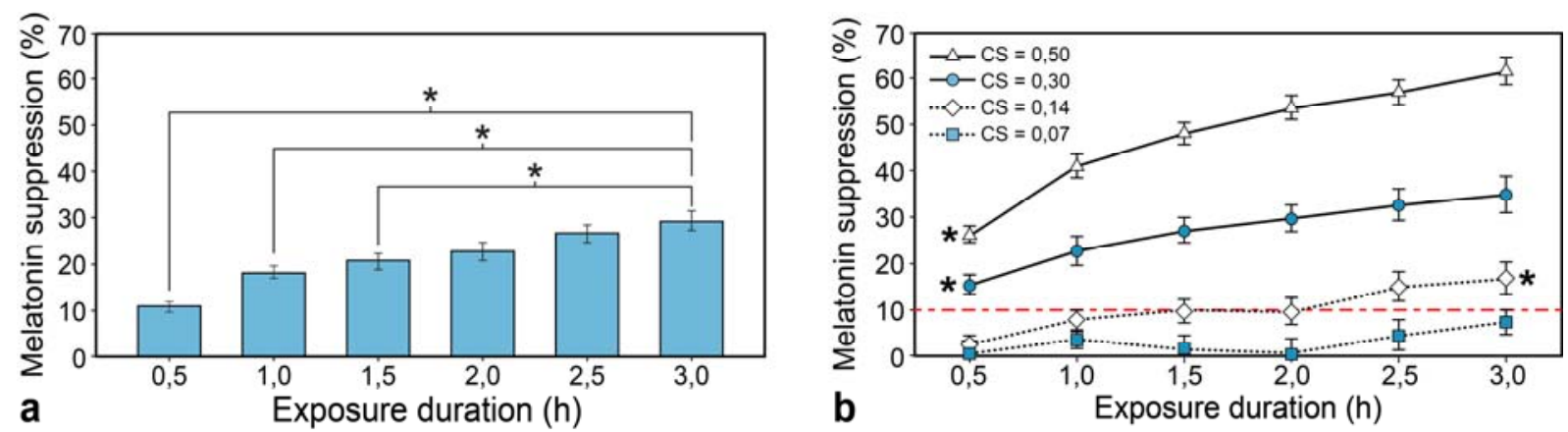

Figure $6-(a)$ The significant main effect of exposure duration. The asterisks represent $p<0,05$ and the error bars represent SEM. (b) The significant interaction between exposure duration and target CS level $(p<0,001)$. Points marked with an asterisk represent the earliest juncture at which melatonin suppression was significantly $>10 \%(p<0,05$, indicated by a dashed line). The error bars represent SEM

\section{Conclusions}

The primary goal of the present study was to measure nocturnal melatonin suppression from a wide range of light levels (40-1000 Ix), 2 white-light spectra $(2700 \mathrm{~K}$ and $6500 \mathrm{~K})$, and extended night-time light exposure durations $(0,5-3,0 \mathrm{~h})$. These data can be used to expand the CS model by Rea and colleagues (Rea et al., 2005, Rea et al., 2012, Rea and Figueiro, 2018) to include light exposure durations longer than $1 \mathrm{~h}$. Further, incorporating additional factors such as participant age can bring us closer to comprehensively characterizing the impact of chronic night-time exposure to electrical lighting on melatonin suppression.

The results show that light's incremental effectiveness for suppressing melatonin diminishes with increasing exposure duration for both age groups and both light sources. The mean absolute percent suppression per hour of exposure, averaged across all other independent variables, was $34,8 \%(1 \mathrm{~h}), 22,2 \%(2 \mathrm{~h})$, and $17,3 \%(3 \mathrm{~h})$, again highlighting the human circadian system's non-linear dose-dependent response to photic stimuli (Chang et al., 2012, St Hilaire et al., 2012, Nagare et al., 2018b). The interaction between exposure duration and CS level further suggests that it takes longer to observe significant melatonin suppression at lower CS levels than at higher CS levels (Chang et al., 2011, Wong et al., 2005).

The lack of an interaction between white light spectra and exposure duration replicates the findings from Nagare et al. (2018b). The efficacy of the $2700 \mathrm{~K}$ source, relative to the $6500 \mathrm{~K}$ source providing stronger short-wavelength stimulation (see Table 2), did not decrease with an increase in exposure duration, supporting the inference that the spectral sensitivity of the participants from both age groups did not change over the 3-h exposure duration. The present results and those from Nagare et al. (2018b) are not in agreement with those from Gooley et al, who reported, using narrowband light sources, that cone photoreceptors only participate in the response during the first 60-90 min and that for longer exposure durations, the response is mediated by the ipRGCs alone (Gooley et al., 2010). The difference in conclusions may be attributed to the fact that Gooley et al. used narrowband light sources and that the response to polychromatic, white light sources may be different, as previously observed by Revell and colleagues (Revell and Skene, 2007, Revell et al., 2010). Another important difference between the 2 studies is that the stimuli employed in the Gooley et al. study were not of the same magnitude. For example, the 460-nm source had a CS $=0,55$ and the 555-nm source had a CS $=0,17$ for the highest light levels. As shown in the present study, there is a significant interaction between stimulus magnitude and duration of exposure, but not between spectral content and duration of exposure. Thus, the significant difference in stimulus magnitude over time in the Gooley et al. study makes it unlikely that there is a change in spectral sensitivity of the circadian system after extended light exposures. Since, however, the duration of exposure and the circadian time of exposure are coincident in both the Gooley et al. study and the present study, it is impossible to know for certain. Additional experiments should be conducted to assess the spectral sensitivity of the circadian system at different times of the night. 
The significant main effect of spectrum was not predicted, given that the stimuli were equated to match CS. These results suggest that the CS model is either over-predicting the response to the $2700 \mathrm{~K}$ source or under-predicting the response to the $6500 \mathrm{~K}$ source. Based on the data from this study and those from Nagare et al. (2018b), it appears that the former is more likely. The CS model formulation assumes that for "cool" polychromatic light sources (e.g. $6500 \mathrm{~K}$ ), Scones contribute to circadian phototransduction through the spectrally opponent blue versus yellow (b-y) colour channel. This formulation closely predicts the $6500 \mathrm{~K}$ data in the present study as it has in previous studies with "cool" polychromatic sources (Figueiro et al., 2005, Figueiro et al., 2006a, Nagare et al., 2018b) and with narrow-band light sources (Brainard et al., 2001, Thapan et al., 2001). The CS formulation assumes a melanopsin-only spectral sensitivity for "warm" polychromatic light sources. This one-photopigment formulation for "warm" sources perhaps ignores, based upon these new data, subtle but important contributions from the photoreceptors distal to the retinal ganglion cells through intervening neural channels. For example, recent studies have shown an inhibitory relationship between cone-photopigments and melanopsin-based photopigments in pupil-size control (Spitschan et al., 2014, Woelders et al., 2018). Subsequent studies should be designed to investigate these interactions more specifically, but in the interim, the CS model formulation for "warm" white light sources should be adjusted to more accurately predict nocturnal melatonin suppression from the present, more extensive study.

As for the heightened sensitivity in adolescents compared to the middle-aged adults, although the results do not statistically support the study's hypothesis and previous findings from our laboratory (Nagare et al., 2018b), the threshold light levels $(C S=0,1)$ were consistently, but not significantly, lower for the adolescents compared to the adults. It is important to view the present results in the context of the mean age of the adult participants (mean [SD] age of 42,4 years $[10,9]$ and 38.7 years $[11,6]$, for study sessions 1 and 2 , respectively), however, who were somewhat younger than the adult participants in the Nagare et al. (2018b) study (mean [SD] age of 46 years [5,2]). Additional research is needed to understand more precisely how agerelated physiological changes affect the light sensitivity of the human circadian system.

The study provided empirical data for estimating an absolute threshold for light's impact on acute melatonin suppression. The threshold criterion used in this study was $C S=0,10$ (equivalent to $10 \%$ melatonin suppression after a 1-h exposure) because, in general, values < $10 \%$ are within the assay measurement error. This threshold criterion was reached for the low light levels only at longer exposure durations. To reach this criterion CS, the $6500 \mathrm{~K}$ white light source would have required exposure to approximately $42 \mathrm{~lx}$ for $3 \mathrm{~h}$; the $2700 \mathrm{~K}$ would have required approximately $95 \mathrm{Ix}$ for $3 \mathrm{~h}$. In light of the present study results, the proposed melatonin suppression threshold of $30 \mathrm{~lx}$ for $30 \mathrm{~min}$ for white light, suggested by Figueiro, Rea, and colleagues in various publications (Bullough et al., 2008, Figueiro and Rea, 2005, Figueiro et al., 2006b, Rea and Figueiro, 2013), appears to be an acceptable, if very conservative, recommendation. However, whether $<10 \%$ melatonin suppression can be deemed as a "safe" criterion for light at night is an idea that requires further consideration and additional research. For example, it is possible that exposure to low levels of light every night for several years might have negative health consequences, but it simply is not known. Notwithstanding, the present results are directly relevant to the American Medical Association's broad recommendation for limiting outdoor lighting CCTs to $3000 \mathrm{~K}$ or lower (American Medical Association, 2016). For night-time outdoor applications, the Illuminating Engineering Society of North America recommends $18 \mathrm{Ix}$ on the horizontal plane, which translates into approximately $9 \mathrm{~lx}$ at the eyes. If one follows these recommendations, the CCT of the light source is irrelevant because exposures to any white light source would be below the threshold for melatonin suppression, even after $3 \mathrm{~h}$ of exposure.

Finally, it should also be acknowledged that although acute melatonin suppression and phase shifting are likely to have the same spectral and absolute sensitivities (i.e. both are sensitive to short-wavelength light, have similar thresholds for response, and have similar saturation levels), their response dynamics are clearly different. Depending upon the outcome measure of interest, different inferences can be drawn about the practical implications of providing light to the human circadian system, even if the light stimulus to the suprachiasmatic nuclei is identical. Therefore, caution should be taken when extrapolating these acute melatonin suppression results to other circadian system outcomes. 


\section{Acknowledgments}

The study was funded by the Jim H. McClung Lighting Research Foundation.

\section{References}

AMERICAN MEDICAL ASSOCIATION 2016. Human and Environmental Effects of Light Emitting Diode (LED) Community Lighting. Council on Science \& Public Health Reports. Chicago, IL: American Medical Association.

BIERMAN, A., KLEIN, T. R. \& REA, M. S. 2005. The Daysimeter: A device for measuring optical radiation as a stimulus for the human circadian system. Measurement Science and Technology, 16, 2292-2299. doi: 10.1088/0957-0233/16/11/023

BRAINARD, G. C., HANIFIN, J. P., GREESON, J. M., BYRNE, B., GLICKMAN, G., GERNER, E. \& ROLLAG, M. D. 2001. Action spectrum for melatonin regulation in humans: evidence for a novel circadian photoreceptor. Journal of Neuroscience, 21, 6405-6412. doi: 10.1523/JNEUROSCI.21-16-06405.2001

BULlOUGH, J. D., BIERMAN, A., FIGUEIRO, M. G. \& REA, M. S. 2008. On melatonin suppression from polychromatic and narrowband light. Chronobiology International, 25, 653-656. doi: 10.1080/07420520802247472

CHANG, A. M., SANTHI, N., ST HILAIRE, M., GRONFIER, C., BRADSTREET, D. S., DUFFY, J. F., LOCKLEY, S. W., KRONAUER, R. E. \& CZEISLER, C. A. 2012. Human responses to bright light of different durations. The Journal of Physiology, 590, 3103-12. doi: 10.1113/jphysiol.2011.226555

CHANG, A. M., SCHEER, F. A. \& CZEISLER, C. A. 2011. The human circadian system adapts to prior photic history. The Journal of Physiology, 589, 1095-102. doi: 10.1113/jphysiol.2010.201194

FIGUEIRO, M. G., BULLOUGH, J. D., BIERMAN, A. \& REA, M. S. 2005. Demonstration of additivity failure in human circadian phototransduction. Neuroendocrinology Letters, 26, 493-498.

FIGUEIRO, M. G., HAMNER, R., BIERMAN, A. \& REA, M. S. 2013. Comparisons of three practical field devices used to measure personal light exposures and activity levels. Lighting Research \& Technology, 45, 421-434. doi: 10.1177/1477153512450453

FIGUEIRO, M. G. \& REA, M. S. 2005. Improving the sleep quality of older adults. Proceedings of the CIE Midterm Meeting and International Lighting Congress 12-21 May, 2005. Spain: Leon Commission Internationale de L'Eclairage.

FIGUEIRO, M. G., REA, M. S. \& BULLOUGH, J. D. 2006a. Circadian effectiveness of two polychromatic lights in suppressing human nocturnal melatonin. Neuroscience Letters, 406, 293-297. doi: 10.1016/j.neulet.2006.07.069

FIGUEIRO, M. G., REA, M. S. \& BULLOUGH, J. D. 2006b. Does architectural lighting contribute to breast cancer? Journal of Carcinogenesis, 5, 20-20. doi: 10.1186/1477-3163-5-20

GOOLEY, J. J., RAJARATNAM, S. M., BRAINARD, G. C., KRONAUER, R. E., CZEISLER, C. A. \& LOCKLEY, S. W. 2010. Spectral responses of the human circadian system depend on the irradiance and duration of exposure to light. Science Translational Medicine, 2, 31ra33. doi: 10.1126/scitransImed.3000741

GÜLER, A. D., ECKER, J. L., LALL, G. S., HAQ, S., ALTIMUS, C. M., LIAO, H. W., BARNARD, A. R., CAHILL, H., BADEA, T. C., ZHAO, H., HANKINS, M. W., BERSON, D. M., LUCAS, R. J., YAU, K. W. \& HATTAR, S. 2008. Melanopsin cells are the principal conduits for rodcone input to non-image-forming vision. Nature, 453, 102-105. doi: 10.1038/nature06829

NAGARE, R., PLITNICK, B. \& FIGUEIRO, M. G. 2018a. Does the iPad Night Shift mode reduce melatonin suppression? Lighting Research \& Technology [Online]. doi: $10.1177 / 1477153517748189$ 
NAGARE, R., PLITNICK, B. \& FIGUEIRO, M. G. 2018b. Effect of exposure duration and light spectra on nighttime melatonin suppression in adolescents and adults. Lighting Research \& Technology [Online]. doi: 10.1177/1477153518763003

PORTALUPPI, F., SMOLENSKY, M. H. \& TOUITOU, Y. 2010. Ethics and methods for biological rhythm research on animals and human beings. Chronobiology International, 27, 19111929. doi: $10.3109 / 07420528.2010 .516381$

REA, M. S. \& FIGUEIRO, M. G. 2013. A working threshold for acute nocturnal melatonin suppression from "white" light sources used in architectural applications. Journal of Carcinogenesis \& Mutagenesis, 4, 1000150. doi: 10.4172/2157-2518.1000150

REA, M. S. \& FIGUEIRO, M. G. 2018. Light as a circadian stimulus for architectural lighting. Lighting Research \& Technology, 50, 497-510. doi: 10.1177/1477153516682368

REA, M. S., FIGUEIRO, M. G., BIERMAN, A. \& HAMNER, R. 2012. Modelling the spectral sensitivity of the human circadian system. Lighting Research \& Technology, 44, 386-396. doi: 10.1177/1477153511430474

REA, M. S., FIGUEIRO, M. G., BULLOUGH, J. D. \& BIERMAN, A. 2005. A model of phototransduction by the human circadian system. Brain Research Reviews, 50, 213-228. doi: 10.1016/j.brainresrev.2005.07.002

REVELL, V. L., BARRETT, D. C., SCHLANGEN, L. J. \& SKENE, D. J. 2010. Predicting human nocturnal nonvisual responses to monochromatic and polychromatic light with a melanopsin photosensitivity function. Chronobiol Int, 27, 1762-77. doi: 10.3109/07420528.2010.516048

REVELL, V. L. \& SKENE, D. J. 2007. Light-induced melatonin suppression in humans with polychromatic and monochromatic light. Chronobiology International, 24, 1125-1137. doi: 10.1080/07420520701800652

SPITSCHAN, M., JAIN, S., BRAINARD, D. H. \& AGUIRRE, G. K. 2014. Opponent melanopsin and S-cone signals in the human pupillary light response. Proceedings of the National Academy of Sciences of the United States of America, 111, 15568-15572. doi: 10.1073/pnas.1400942111

ST HILAIRE, M. A., GOOLEY, J. J., KHALSA, S. B., KRONAUER, R. E., CZEISLER, C. A. \& LOCKLEY, S. W. 2012. Human phase response curve to a $1 \mathrm{~h}$ pulse of bright white light. The Journal of Physiology, 590, 3035-3045. doi: 10.1113/jphysiol.2012.227892

THAPAN, K., ARENDT, J. \& SKENE, D. J. 2001. An action spectrum for melatonin suppression: Evidence for a novel non-rod, non-cone photoreceptor system in humans. The Journal of Physiology, 535, 261-267. doi: 10.1111/j.1469-7793.2001.t01-1-00261.x

WOELDERS, T., LEENHEERS, T., GORDIJN, M. C. M., HUT, R. A., BEERSMA, D. G. M. \& WAMS, E. J. 2018. Melanopsin- and L-cone-induced pupil constriction is inhibited by Sand M-cones in humans. Proceedings of the National Academy of Sciences, USA, 115, 792-797. doi: 10.1073/pnas.1716281115

WONG, K. Y., DUNN, F. A. \& BERSON, D. M. 2005. Photoreceptor adaptation in intrinsically photosensitive retinal ganglion cells. Neuron, 48, 1001-1010. doi: 10.1016/j.neuron.2005.11.016 